\title{
The Shipwreck (Navagio) of Zakynthos: Decay \& Preservation. A First Approach
}

\author{
Adamantia Panagopoulou ${ }^{1,2 *}$, Christos Karydis ${ }^{3}$, Maria Bratitsi ${ }^{4}$, Nikolaos Salamouris $^{3}$, Adamantia Kampioti ${ }^{3}$, \\ Georgia Platipodi ${ }^{3}$ and Katerina Kabassi ${ }^{3}$ \\ ${ }^{1}$ Department of Archaeology, University of Leiden, The Netherlands \\ ${ }^{2}$ Institute of Nanoscience and Nanotechnology "Demokritos" National Center for Scientific Research, Greece \\ ${ }^{3}$ Department of Environment Division: Conservation of Antiquities \& Works of Art, Ionian University, Greece \\ ${ }^{4}$ Lab of Archaeometry, Department of Mediterranean Studies, University of the Aegean, Greece
}

*Corresponding author: Adamantia Panagopoulou, Department of Archaeology, University of Leiden, The Netherlands and Institute of Nanoscience and Nanotechnology "Demokritos" National Center for Scientific Research, Athens, Greece

\begin{abstract}
The Shipwreck (Navagio) is the most important touristic attraction of Zakynthos island in Greece and its fame radius is expanding on a global scale. It is a $20^{\text {th }}$ century ship that in 1982 stray to a particularly inaccessible beach in the northwestern part of Zakynthos island. The particular sight is ranked every year very high on the lists of the most widespread destinations on a global scale. Although, it is a new ship it has received extensive publicity as cultural property of Greece. The main construction materials of Navagio is the metal, wood, and paints that have been used in the decoration of the ship. The Navagio is exposed and suffer every year to extreme environmental factors i.e temperature, humidity, salts, further vandalism, etc. The main aim of this paper is the attempt to document the agents of deterioration, which rabidly destroy this ship and compare the levels of deterioration and preservation state with other shipwrecks in Greece in order to warn the owners or the involved institutions for its future preservation.
\end{abstract}

keywords: Shipwreck; Zakynthos; Preventive Conservation; Documentation; Metal; Wood; Corrosion

\section{Introduction}

The Mediterranean Sea has numerous shipwrecks which are exposed to various environmental conditions similari to Navagio in Zakynthos such as in Gytheio- Peloponnese etc. The particular shipwreck in Zakynthos is a unique specimen of ship on a coast, in contradiction with the majority of shipwrecks with metal or wooden core that were discovered underwater.

Specifically, Navagio or Shipwreck (Figure 1), which casted away in 1980, is an exposed cove, sometimes re-ferred to as «Smugglers Cove», on the coast of Zakynthos, in the Ionian Islands of Greece. Navagio beach was originally known as Agios Georgios. It is located to the northwest of the island Zakynthos (Figure 2) near the mountain village of Anafonitria, at the area Volimon. On $2^{\text {nd }}$ of October in 1980, a Freightliner, the MV Panagio-tis, which previously had three different names such as Meropi, Charis and Nikos with NP code 4512 and total capacity 452,24 cubic meter, was aground in the waters around Zakynthos Island on Navagio
Beach during stormy weather and bad visibility. The Shipwreck (Navagio) is the most important touristic attrac-tion of Zakynthos island in Greece and its fame radius is expanding on a global scale. The par-ticular sight is ranked every year very high on the lists of the most widespread destinations on a global scale. Although, it is a new ship it has received extensive publicity as cultural property of Greece.The aims of this paper are:

a) To present the current preservation state of the Navagio,

b) To underline the main deterioration agents,

c) To compare with other similar or underwater shipwrecks in Greece or in other countries,

d) To analyse the main construction materials of Navagio such as iron and wood using sophisticated analysis,

e) To document the environmental condition and

f) To propose future preservation plan. 


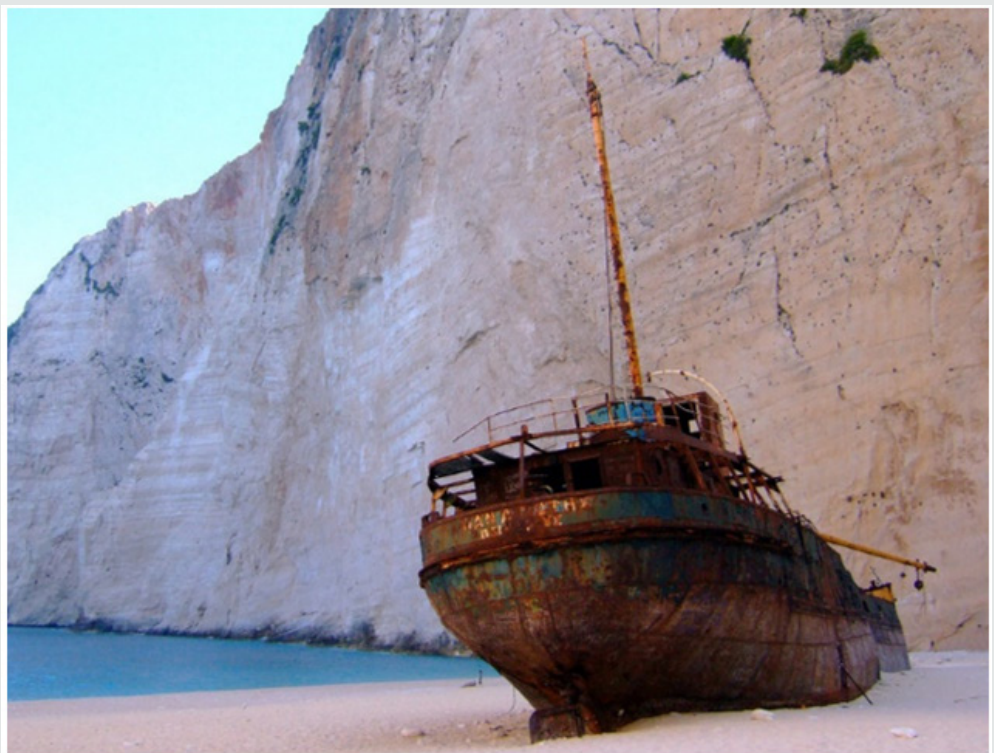

Figure 1: The Shipwreck (Navagio) in Zakynthos island, Greece.

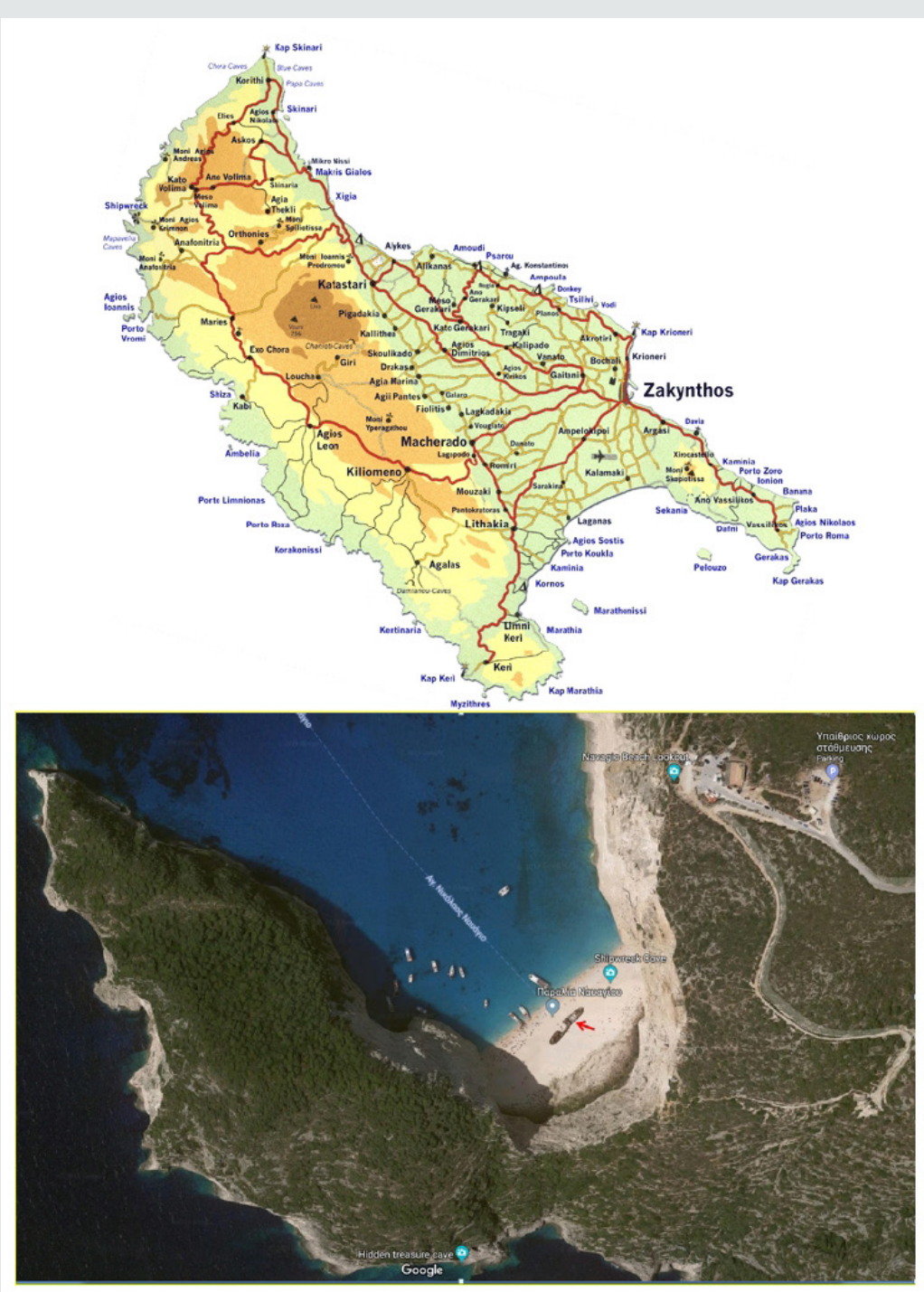

Figure 2: Navagio location through the Google® map. 


\section{Other Swipwrecks}

Even though there are many examples of such shipwrecks, the activities of man can affect this kind of coastal sites. One of the examples is the Contarina site near Rovigo (Italy) where the remains of two ship hulls, Contarina I and Contarina II, were discovered inland, (Figure 3). Similar example is the shipwrecks in Laguna Tantura in Israel (Figure 4), most of them were discovered in shallow waters, covered in a thick layer of sand, there are 26 shipwrecks recorded but only nine of them have been excavated (Tantura A, B, E and F, DW 2, Dor C, Dor D, Dor 2001/1 and Dor 2002/2).

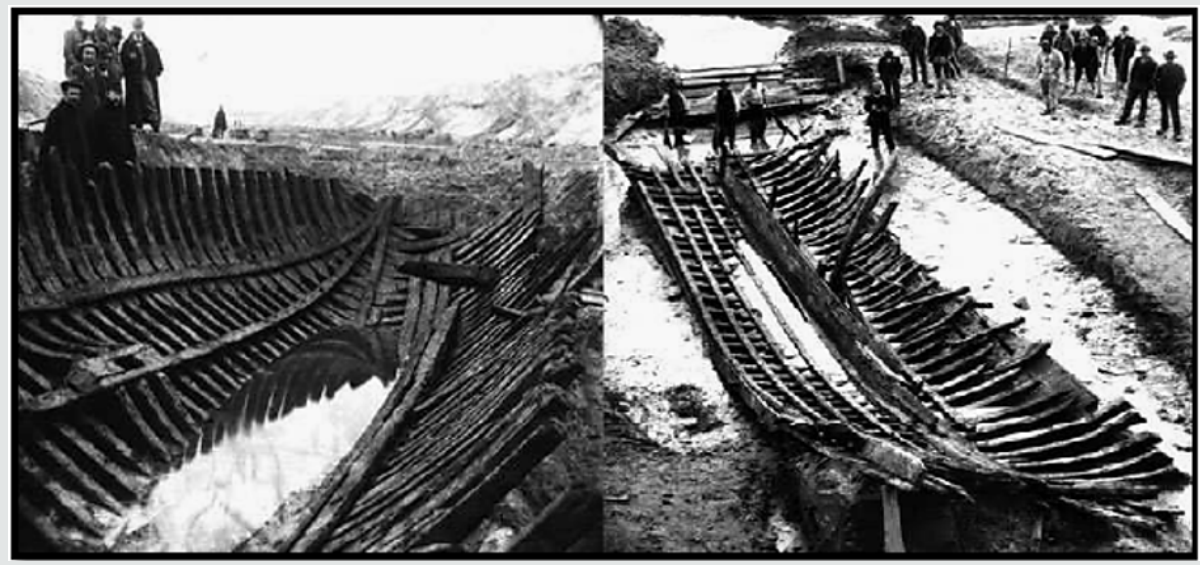

Figure 3: Contarina I \& II [1].

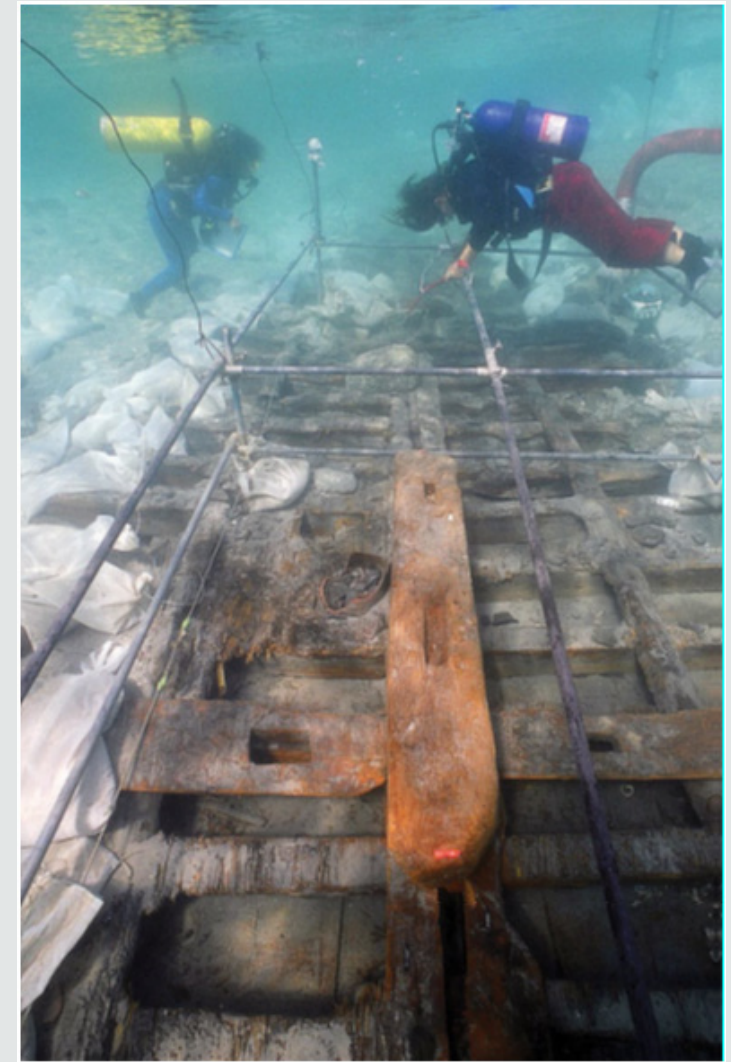

Figure 4: Tantura F Shipwreck, Tantura Lagoon, Israel [2].

Moreover, ancient shipwrecks were discovered in 2012, in the open sea between Corfu and Paxos Is-land in the Ionian Sea. Archaeologist Dr. D. Kourkoumel is confirmed three shipwrecks, (in 1.260 to $1.800 \mathrm{~m}$. depth), that was named Poseidon 1, 2 and 3. Poseidon 1 and 2 are placed chronologically in the $3^{\text {rd }}$ century A.D., during the Roman period. Ceramic, marble and metallic findings were collected, some of them may be parts of their core. Poseidon 3 is probably from the $17^{\text {th }}-18^{\text {th }}$ century and the main part of its core is saved, such as ceramic artifacts and various objects. These shipwrecks are characterized as the deepest found ship-wrecks in the Mediterranean Sea $[1,3,4]$. 
Finally, in Gytheio (Peloponnese-Greece) in the Selinitsa beach (the locals name this particular spot of the beach "Valtaki") a shipwreck was found on the coast (1981), (Figure 5). At first, the ship "Dimitrios" was abandoned by its crew in the port of Gytheio, even though the ship was private property, the owners left it there. Through the time the shipwreck moved in its current position on the coast and became a tourist attrac-tion. The bottom of the ship is placed inside the sea, covered by sand with the main core standing out of the water such if it was its original place. Even though the similarities with the "Navagio" in Zakynthos are ap-parent, their placement is different, since "Dimitrios" shipwreck is partly underwater [5].

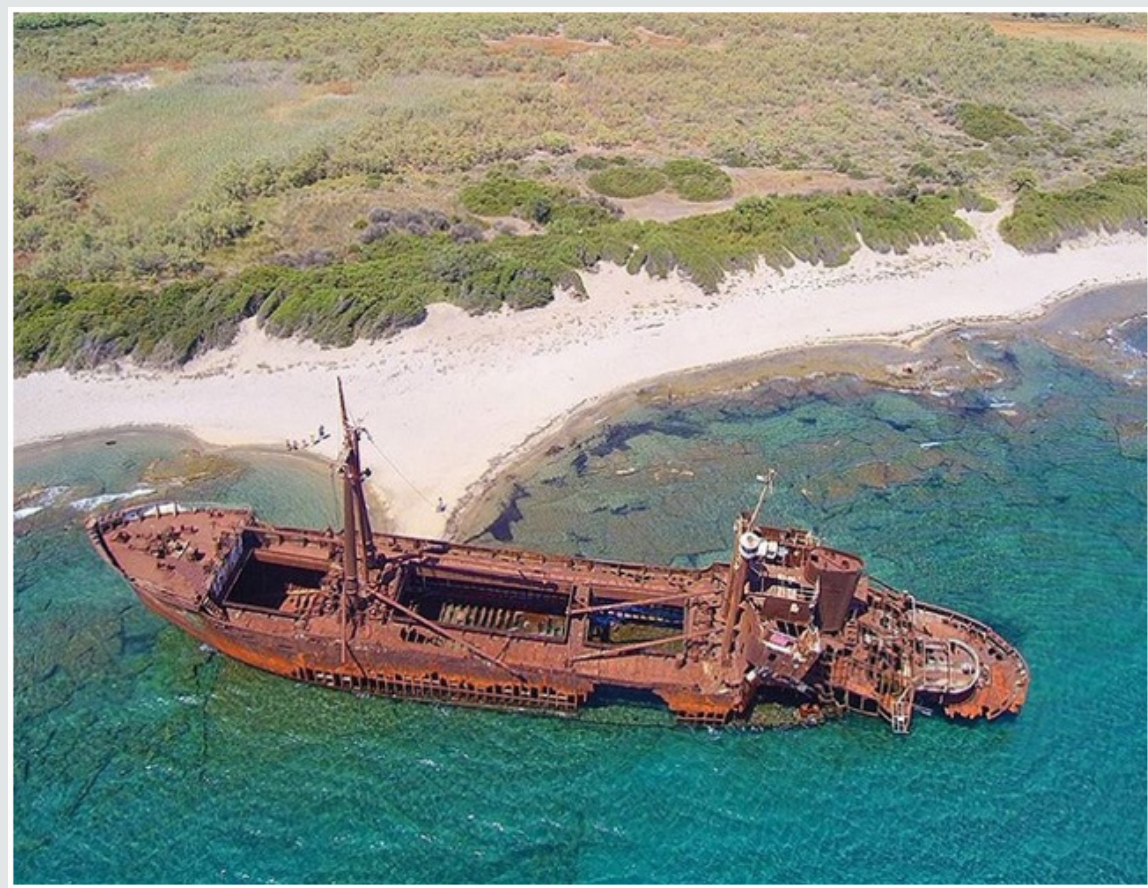

Figure 5: "Dimitrios" Shipwreck in Gytheio, Greece (Photograph Happy Traveler® Website http://happytraveller.gr/ navagio-dimitrios/)

\section{Surveying Documentation: A Step Before Preservation}

Before any action could be taken, thorough documentation and extensive study should be made in order to define the exact position, its actual form, the stability, the materials and the damage of the object. The Surveying Documentation of cultural heritage objects serves as a tool to make information accessible to those (research experts or any interested persons) who cannot investigate the object itself. Furtherome, the main problems of Navagio during documentation are:

a) The object is not accessible to researchers. Actually, according to the latest law (FEK 907/15.03.2019) the beach is not accessible to anyone taking into consideration the recent earthquake and the fallen of a large rock. All the boats are just approaching the coast but not the ship.

b) The object is too large or too complicated to study and it would be too time-consuming to execute an own investigation.

c) The object (or just a part of it) is visible only for a short period of time at its original location (as in archae-ological excavations or when unearthed during civil engineering projects).

d) The object is in danger of slow deterioration (environmental factors) or sudden destruction (earthquakes, other natural disasters, and vandalism).

For the geometric recording several surveying methods may be applied, ranging from the simple topometric methods to the elaborated contemporary surveying and photogrammetric methods. Traditionally, for reasons related to financial restrictions and to "scientific responsibilities", simple topometric methods were the pre-ferred ones. However, the negative experiences from the application of these methods, the technological ad-vancements in the field of surveying and photogrammetry and the inevitable international trends have im-posed a complete change in this mentality. Today in geometric documentation of monuments the following methods are applied:

a) Simple topometric methods for partially or totally uncontrolled surveys

b) Surveying and photogrammetric methods for completely controlled surveys 
The simple topometric methods are applied only when the dimensions and complexity of the object may al-low it when an uncontrolled survey is adequate, or in cases when a small completion of the fully controlled methods is required.

Surveying and photogrammetric methods are based on direct measurements of lengths and angles, either on the monument or on images thereof. They determine three-dimensional point coordinates in a common reference system and ensure uniform and specified accuracy. Moreover they provide adaptability, flexibility, speed, security, and efficiency. All in all they present undisputed financial merits, in the sense that they are the only methods, which may surely meet any requirements with the least possible total cost and the biggest total profit.

In the case study of Shipwreck, contemporary surveying and photogrammetric methods for the geometric documentation of a monument are recommended to be applied in combination. The required percentage of each one in each case depends on the accuracy specifications and on the level of detail, i.e. the qualitative in-formation, of the object required for the final product. The two methods contribute to the final product. Classi-cal survey measurements provide an accurate determination of specific points, which form a rigid framework within which the Shipwreck details from the photogrammetric survey are being placed. This framework pro-vides strong interrelations of the measured points in 3D space, necessary as a base for the photogrammetric procedures.

In the future geometric documentation should be considered as an integral part of a greater action, the Gen-eral Documentation of the Cultural Heritage. This comprises, among others, the historical documentation, the architectural documentation, the bibliographic documentation, etc. The geometric documentation of Ship-wreck consists of a series of measurements, from which visual products such as vector drawings, raster imag-es, 3D visualizations, etc. may be produced. These products have usually metric properties, especially those being in suitable orthographic projections. Hence one could expect from the geometric documentation a series of drawings, which actually present the ortho projection of Shipwreck on horizontal or vertical planes. These should be carefully defined at the outset, before any action on Shipwreck. The scale of the final product im-plies, in turn, the level of detail, which should be present.

Nowadays, it is possible to produce highly accurate measurements of single points, collect point clouds de-scribing any surface and determine the form, size, and position of any detail, however complicated, from con-ventional or digital photographic images. The possible products comprise two-dimensional or three-dimensional vector or raster drawings in printed or digital form. The photogrammetric methodology is capa-ble of providing adequate overall accuracy common for all points measured and details surveyed. Lately, the laser scanner technology has been employed for the benefit of geometric recording of monuments with highly promising results.

The technological advancements have enabled the threedimensional visualizations of the monuments on the computer screens. The compilation of 3D models of archaeological monuments is considerably facilitated by the usage of dense point clouds, which are created by the use of terrestrial laser scanners. Their combined use with photogrammetric procedures, such as the production of orthophotos, allows the realistic 3D represen-tation of complex monuments (i.e. sculptures).

Cultural heritage recording and documentation comprises a wide field of objects, disciplines, and technolo-gies. Because of those large diversities, every project is different. This makes the task difficult. Co-operation be-tween different scientific and professional disciplines is necessary. On the other hand, these requirements make it very challenging and rewarding to work in this field.

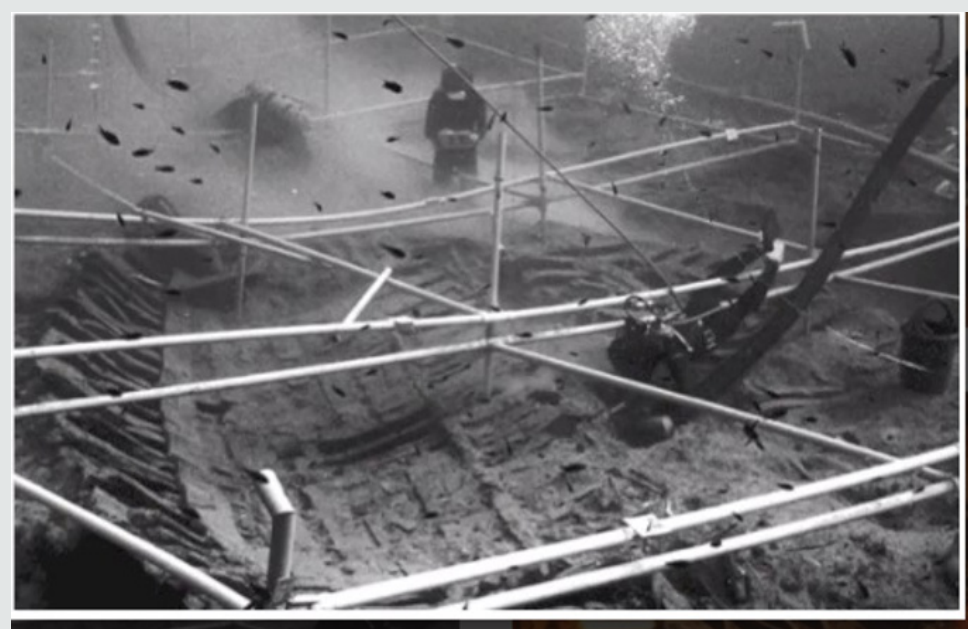

Recording the hull timbers on the seabed (Photo: Susan Katzev). REF4242

Figure 6: Kyrenia Shipwreck [6]. 
Even in primer scientific studies, recorded shipwrecks needed multi-professional teams to achieve a com-plete survey, a noticeable example of the late '60s is the Kyrenia Ancient Greek Ship in Cyprus (Figure 6). The excavation was conducted by Susan Womer Katzev and Michael Katzev, where a 54 member team from differ-ent fields recorded the shipwreck using stereo photos, manual triangulation and multiple surveying methods to collect as much information as possible. Navagio Shipwreck may be more approachable than the Kyrenia shipwreck, but the fact that they are unique specimens from different eras make them important findings that need extent research and multiple scientific approaches [7].

\section{Agents of Deterioration}

\section{General preservation state}

During the short autopsy, observation was taken not only for the main construction materials of the ship such as metal and wood but also for the entire future stability of the ship taking into consideration the extreme changes of the environmental conditions where it acts as a suppressor in further future preservation of the ship.
Strong or weak Northwest winds and falling temperatures in the winter months, as well as increased temperature (over $36^{\circ} \mathrm{C}$ ) and humidity levels (over 68\%) during the summer and winter months, create a fur-ther instability in the preservation of both inorganic (metal, paints) and organic (wood) exposed construction materials of the Shipwreck. During winter the ship suffers from mechanical \& chemical decay coming from the sand, salts, and water (Figure 7). The strong north-west winds and the wave accelerate the deterioration of the metal surface. Furthermore, the see salt -spray increase the chemical decay with the metal parts but also with the remain paints (pigments) where they have been applied to the outer shell of the ship. Furthermore, mechanical decay is also caused from the everyday vandalism of the tourists (scratches, paints, stickers, sprays, etc.), (Figure 8) during the summer period and also the entrance of many tourists inside the ship. The recommendation is if it is possible in the future to measure continuously the RH levels and the UV radiation which the ship is exposed giving further information for the future level of the deterioration.

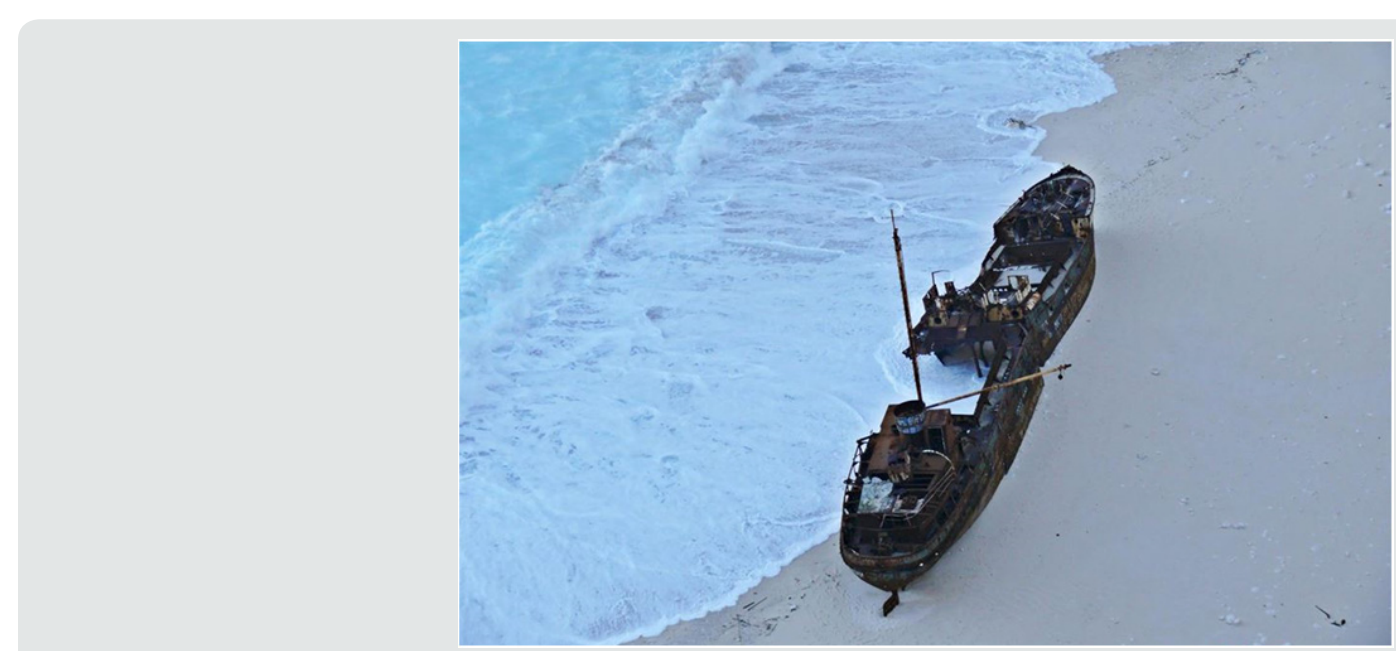

Figure 7: The Navagio during the winter period (Photo by D. Lykogiannis).

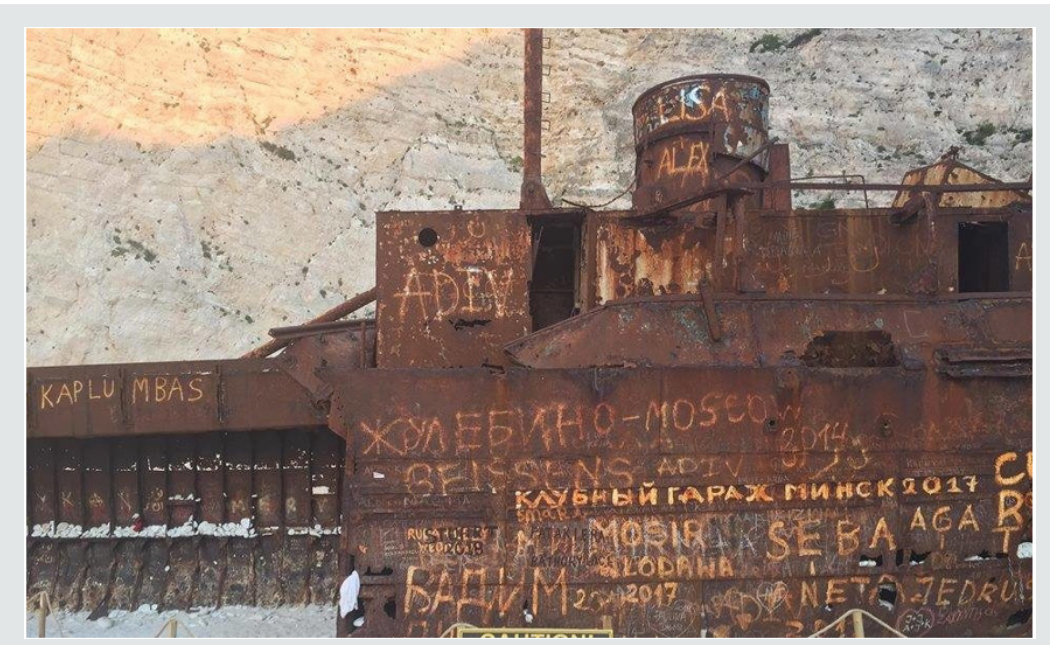

Figure 8: Vandalisms caused by the tourists on the surface of the ship mainly during the summer period. 


\section{Iron corrosion}

Iron consist to be the main construction material of Navagio. Metal identification through physicochemical analysis is an important and necessary step, as it gives a specific direction for the preservation statue as and conservation process in order to choose appropriate materials and methodology. The use of the stereoscope is a very useful detailed observation instrument, particularly for a first verification of the alloy components. The procedure was nondestructive and was done with Stereo Microscope Leica ${ }^{\circledR}$ M205FA (160x), with fixed focus 7,8x, on all shots [8].

The purpose of the analysis with Xray fluorescence spectroscopy is quantitative and qualitative documenta-tion of the ship. The verification of the alloy components, in the construction metal of the ship, provides infor-mation that is a criterion for the proper information about preservation statue. The analysis was carried out with XRF, Thermo Scientific Niton $®$ XL3 + GOLDD (Mantler et al., 2000; Beckhoff et al., 2006; Liritzis, 2011). According to XRF analysis, the metallic part of the shipwreck consists of the following elements: (Table 1).

Table 1.

\begin{tabular}{|c|c|c|c|c|c|}
\hline $\mathbf{F e}$ & $\mathbf{C a}$ & $\mathbf{M n}$ & $\mathbf{S}$ & $\mathbf{A l}$ & $\mathbf{S i}$ \\
\hline $60.22 \%$ & $2.64 \%$ & $0.35 \%$ & $0.36 \%$ & $0.33 \%$ & $0.19 \%$ \\
\hline $\mathbf{K}$ & $\mathbf{C r}$ & $\mathbf{C u}$ & $\mathbf{N i}$ & $\mathbf{A s}$ & $\mathbf{S n}$ \\
\hline $0.08 \%$ & $0.08 \%$ & $0.05 \%$ & $0.04 \%$ & $0.02 \%$ & $0.02 \%$ \\
\hline
\end{tabular}

Finally, the basic chemical element of the metallic part of the ship is Fe (60.22\%). The corrosion mechanism of the Shipwreck in Zakynthos is described below [9-11]: When the iron is eroded, the iron dissolution reaction (the anodic half-reaction is $\mathrm{Fe} \rightarrow \mathrm{Fe}^{2+}$ $\left.+2 \mathrm{e}^{-}\right)$occurs at the interface between the metal and the corrosion products.

In aqueous solutions with a $\mathrm{pH}$ higher than 4 , this half-reaction is offset by the reduction of dissolved oxygen (the cathodic halfreaction is $\mathrm{O}_{2}+2 \mathrm{H}_{2} \mathrm{O}+4 \mathrm{e}^{-} \rightarrow \mathrm{OH}^{-}$). Iron (II) ions are formed on the iron surface, dissolved, circulated and hydrolyzed (for example, $\mathrm{Fe}^{2+}+\mathrm{H}_{2} \mathrm{O} \leftrightarrow \mathrm{Fe}(\mathrm{OH})^{+}+\mathrm{H}^{+}$) causing local acidification of the solution. Electrical neutrality could be maintained, and this can be achieved by anions (for example, chlorine ions) diffused from the surrounding environment to balance the load of cations $\mathrm{Fe}^{2+}$

Chlorine ions tend to concentrate on the interface due to their high mobility and because they are often the most prevalent environmental anions, especially in a marine environment. The degree in which chlorine ions are absorbed depends on the $\mathrm{p}^{\mathrm{H}}$. The maximum absorption of chlorine ions is done at a low $\mathrm{p}^{\mathrm{H}}$.
The final results are the cracks, pores and open cavities inside the corrosive layer of the archaeological iron which are filled with an acidic solution of iron chloride (II). Other corrosion products are likely to form on the metal surface, depending on the $\mathrm{pH}$, the oxygen and the presence of carbonate and phosphate ions, as ferrite or vivianite [9-11].

When the iron is exposed to the air and allowed the acidic solution $\mathrm{FeCl}_{2}$ is compacted, the corrosion products are hydrolyzed and there is a high amount of oxygen: $\mathrm{Fe}^{2+}$ ions in the solution react with oxygen and water and take the form of ferrous corrosion products (III) and new compounds:

$$
\begin{aligned}
& 2 \mathrm{Fe}^{2+}+3 \mathrm{H}_{2} \mathrm{O}+\mathrm{O}_{2} \leftrightarrow 2 \mathrm{FeOOH}+4 \mathrm{H}^{+}[1] \\
& \text { or } 2 \mathrm{FeCl}_{2}+3 \mathrm{H}_{2} \mathrm{O}+\mathrm{O}_{2} \leftrightarrow 2 \mathrm{FeOOH}+4 \mathrm{HCl}[2]
\end{aligned}
$$

$\mathrm{FeOOH}$ is solid and can cause physical damage to the object because it forms inside the surface layers, causing stresses and cracks. The other product is acid and causes chemical corrosion to the object because it reacts with the pure metal and oxidizes it.

The $\mathrm{FeOOH}$ may be Goethite $(\alpha-\mathrm{FeOOH})$ or Lepidocrocite $(\gamma-\mathrm{FeOOH})$ or Akaganeite $(\beta-\mathrm{FeOOH})$. Akaganeite needs many chlorine ions to stabilize its structure. The formation of these three corrosion products in the corrosion layers causes mechanical damage. This is because these corrosion products have a volume three times larger than iron. The Akaganeite is formed into elongated particles and causes more mechanical damage than other products. The chemical corrosion comes from $\mathrm{FeCl}_{2}$ that oxidizes in $\mathrm{FeOOH}$ with the result of the continuous appearance of $\mathrm{HCl}$, according to reaction 3 :

$$
\mathrm{Fe}+2 \mathrm{HCl}+\mathrm{O}_{2} \leftrightarrow \mathrm{FeCl}_{2}+\mathrm{H}_{2} \mathrm{O}[3]
$$

The second step is the oxidation of $\mathrm{FeCl}_{2}$ to $\mathrm{FeOOH}$ and the subsequent appearance of $\mathrm{HCl}$ :

$$
2 \mathrm{FeCl}_{2}+3 \mathrm{H}_{2} \mathrm{O}+\mathrm{O}_{2} \leftrightarrow 2 \mathrm{FeOOH}+4 \mathrm{HCl}[4]
$$

This process is called acid regeneration cycle. What is to be understood is that chlorine ions produce a soluble iron salt [9-11]. It is also recognized active iron corrosion on the surface of the ship, which is the result of the formation of iron chloride (II), which has the following characteristics:

a) spalling.

b) cracks, powdered slag.

c) loose slag flakes around the object.

d) red-brown corrosion products at loosen points.

e) tears (drops) on the surface of the object (Figures $9 \& 10$ ). 


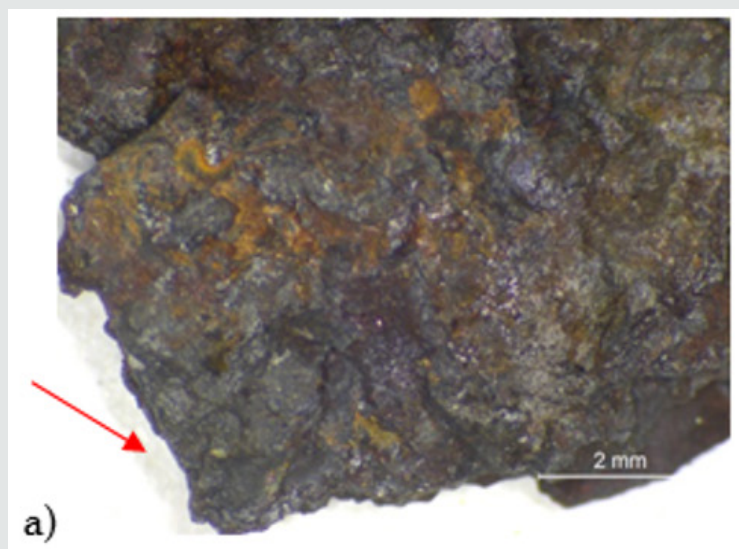

b)

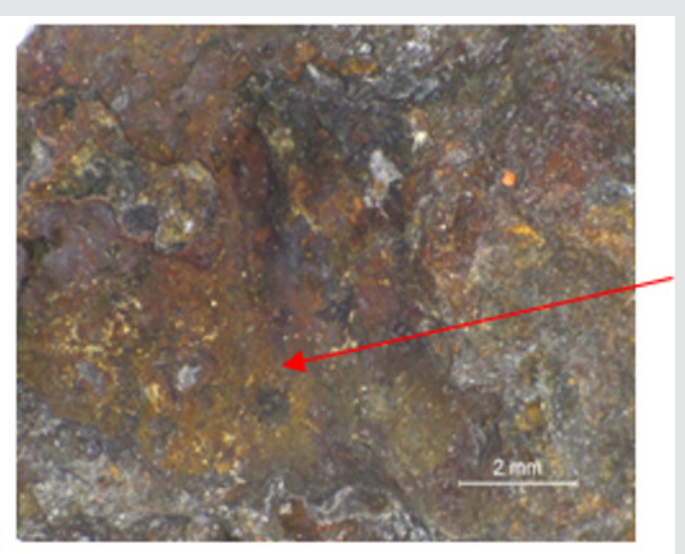

Figure 9: a) Spalling, b) red-brown corrosion products on the metallic surface.

a)

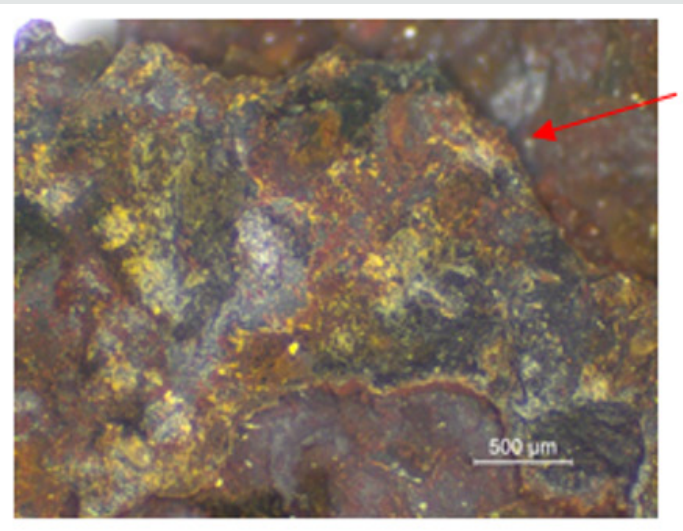

b)

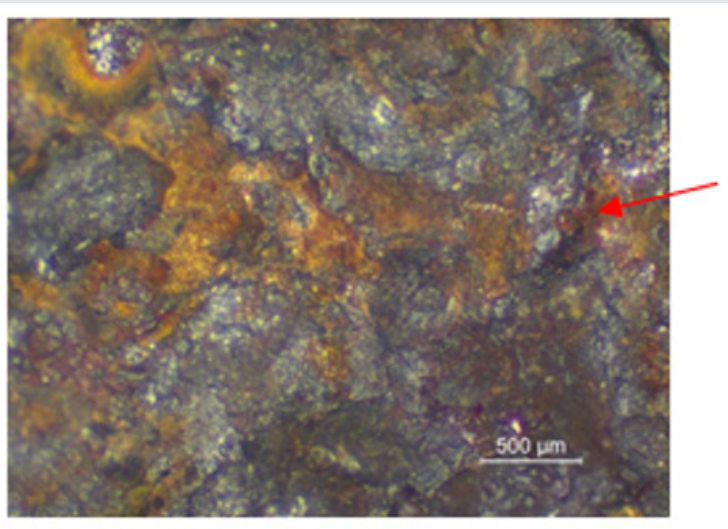

Figure 10: a) Loosen slag flakes around the object, b) tears (drops) on the surface of the object.

On the surface of the ship is observed Iron that "tears" which is a visible symptom indicating that a corrosion process occurs in this iron object. The "tear" is due to the hygroscopic nature of the iron chloride salts. $\mathrm{FeCl}_{2}$ crystals are formed under the following conditions:

a) $18-56 \% \mathrm{RH}: \mathrm{FeCl}_{2} \cdot 2 \mathrm{H}_{2} \mathrm{O}$ is formed

b) over $56 \% \mathrm{RH}: \mathrm{FeCl}_{2} \cdot 4 \mathrm{H}_{2} \mathrm{O}$ crystals absorb moisture resulting in the formation of spherical shaped drops

c) Iron (II) in solution is oxidized to one of $\mathrm{FeOOH}$ oxides. d) If the liquid evaporates, a cavity remains on the surface of the metal.

Furthermore, Akaganeite is formed by the presence of high concentrations of chlorine ions and only when the iron object is exposed to the air. Its presence indicates that the object is heavily contaminated with chlorides. Red-brown corrosion products at points of surface rupture are usually Akaganeite $(\beta-\mathrm{FeOOH})$. It is a specific type of oxide with a structure stabilized by chlorides. Furthermore, up to the external corroded layer, some areas of pigments with green, red, blue and light blue colors are totally corroded [9-11],(Figure 11).
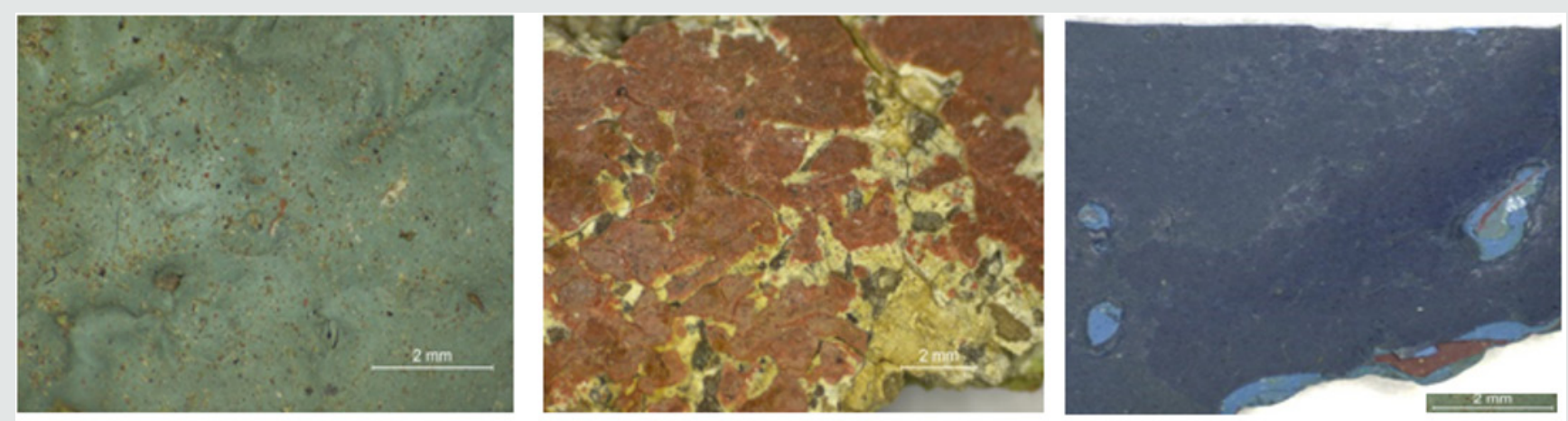

Figure 11: The corrosion levels of the pigments on the metallic surface using Optical Microscopy.

Citation: Adamantia P, Christos K, Maria B, Nikolaos S, Adamantia K, et al., The Shipwreck (Navagio) of Zakynthos: Decay \& Preservation.

A First Approach. J Anthro \& Archeo Sci 1(5)- 2020. JAAS.MS.ID.000124. DOI: 10.32474/JAAS.2020.01.000124 
To sum up, the shipwreck as marine iron usually exhibits a stratigraphic structure of corrosion products. The outer layer is a mixture of iron corrosion products, such as goethite, and foreign materials such as small stones, sand, and soil and fish shells deposits. Below this, there is another layer of iron corrosion products in a lower oxidation state, usually magnetite, on the remaining metal. Up to the external corroded layer, some areas of pigments exist with green, red, blue and light blue colors. The most of the pigments corroded and in many areas pigments completely are lost.

\section{Wood decay}

Only a very few parts compared to its total volume (Figure 12), like the planks as a floor on the bridge, the lower parts of the deck's metal floors as a support to the beams and the rudder on the bow outside of the ship are made of wood (Figure 13A\&B).
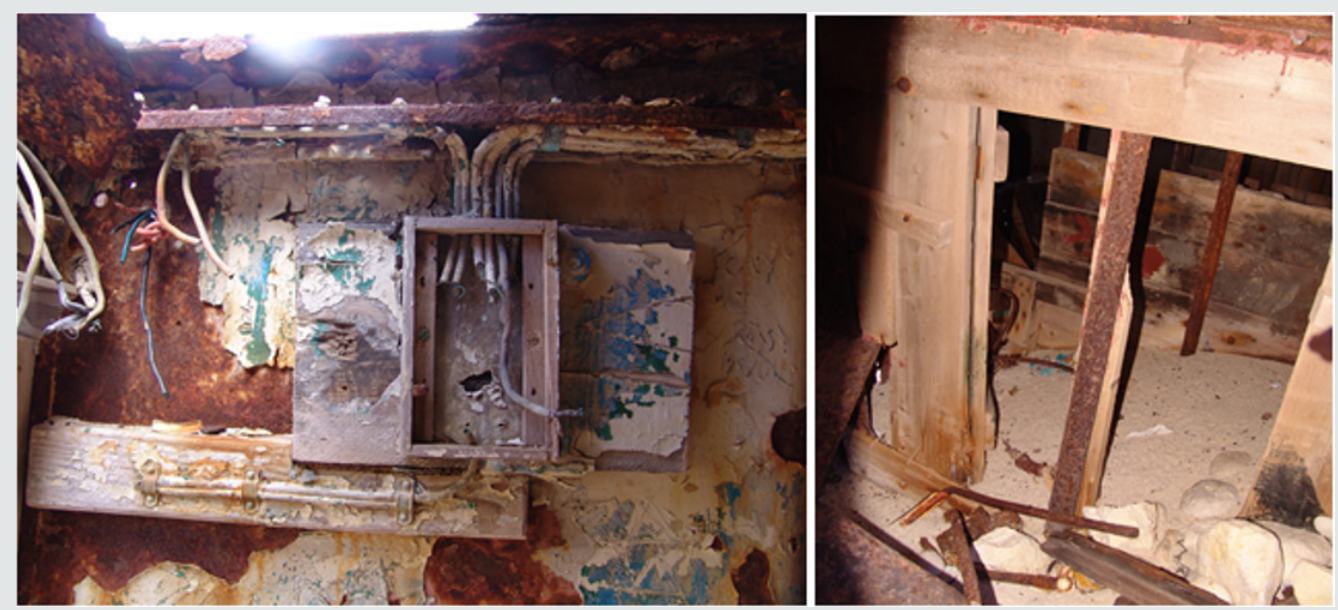

Figure 12: Details of decayed wooden parts inside the ship.

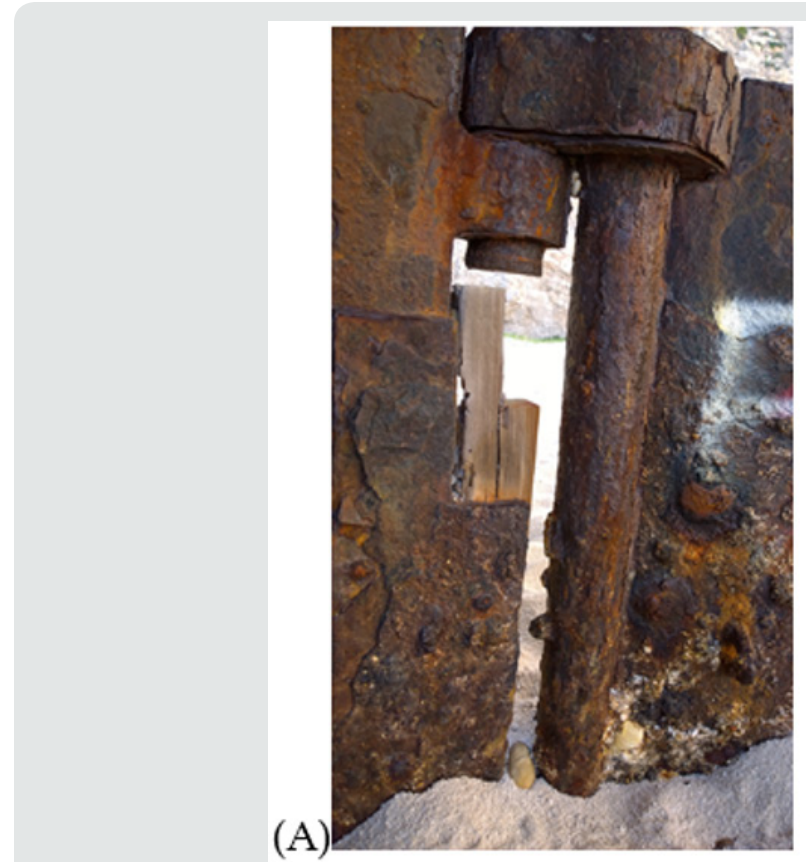

(B)

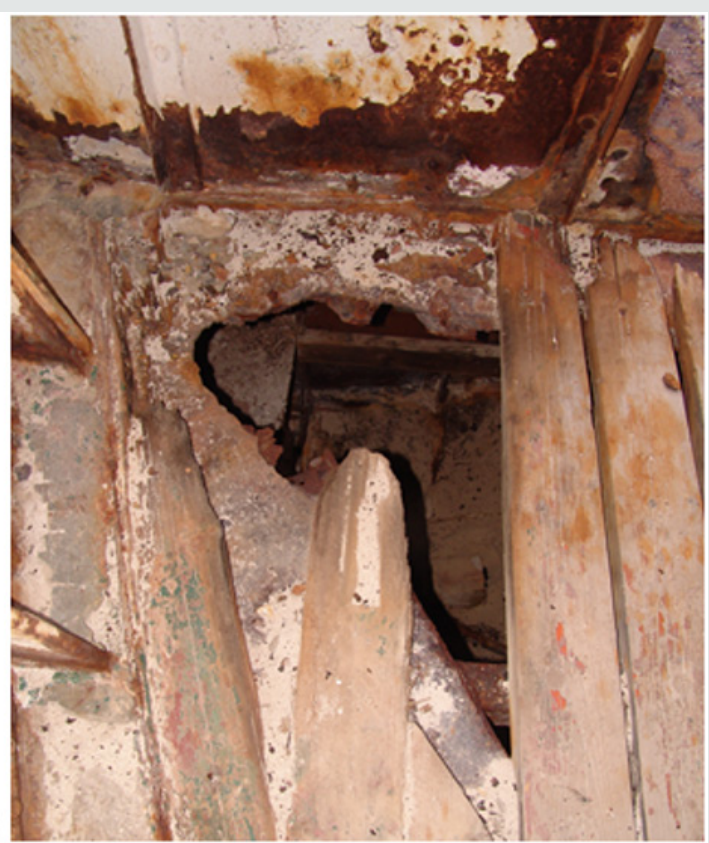

Figure 13: (A) Details from the wooden remains of the rudder on the bow outside of the ship and (B) the floor on the bridge.

Wood is a reliable material for use in an environment close to the sea since it is neither polymerized nor anodized, but it must also be a special hardwood in order to be resistant to specific conditions. In the case of the Navagio wreck, wooden parts constitute a very less percentage of the entire ship, so they can be made from any kind of wood, even a soft one, therefore more susceptible and sensitive. This is obvious by the microscopic cellular structure that has been made by a very small piece of wood that was lying by the ship and was observed via a polarized microscope (Nikon® E200 - 100X). The transversal section (Figure 14A) is compact and without vessels, a definite indication of Coniferous wood. Large resins canals with thin-walled epithelial cells, shown at the tangential section (Figure 14B) probably indicate a pine tree, although the piece of wood was quite moldy. 
(A)

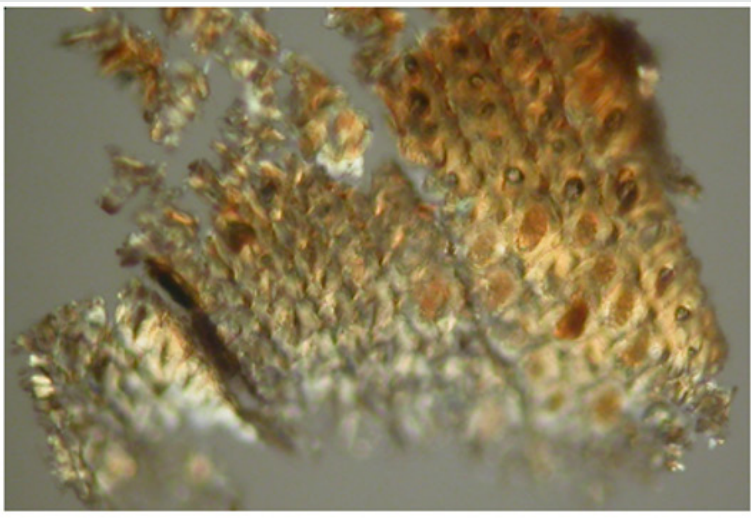

(B)

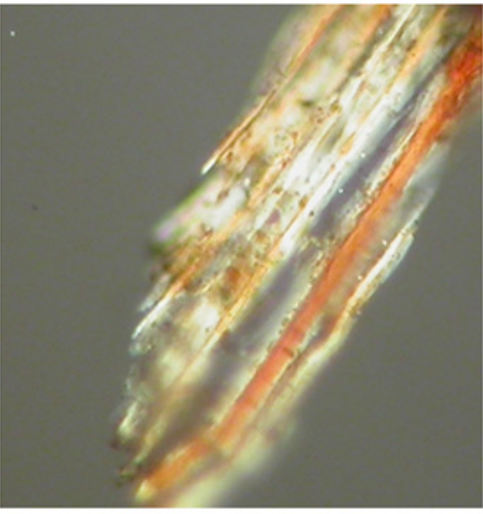

Figure 14: Microscopic (magnification of 100x) Cellular Structure of (A) transversal and (B) tangential section of wood.

Wood has a variable structure and properties, making it particularly sensitive to the prevailing environmental conditions. Especially softwoods contain alternate layers of earlywood, which has a low density, and latewood, which has a density three times greater. This structure, therefore, has the disadvantage of alternate weak and strong layers, making it a very vulnerable material and in constant dependence with the environmental changes. The wreck has been exposed for over thirty years on a beach with weather conditions extremely changing, not only over the years but also during the day. Every winter the sea covers the entire ship for a few months, while in the summer the water subsides exposing it to direct sunlight and causing abrupt drying and wide-spreading mustiness while making it even softer. This means that the wreck is exposed to two very different environments causing significant damage to the wooden parts of the ship, although surprisingly well preserved, compared to the metal parts. This is due to the fact that the wooden elements are in places protected by the direct contact with the sun and the sand, but mainly they are hardly accessible by the tourists. This shows the necessity of interrupting this interactivity of tourists with the ship, which causes the most significant damage. A unique example of management in a similar situation is the Cavtat Shipwreck in Croatia, which is one of the first underwater sites that are presented to the public, through the deployment of protective cages. The public can visit the site, but not interact with the findings unless they are authorized, researchers. Even though the Navagio Shipwreck is on the coast, the containment of the site from the public is of the essence in order to preserve the ship, [12].

Wood is hygroscopic, so it absorbs or eliminates moisture in order to balance with the surrounding environment. It also exhibits anisotropy and heterogeneity, that is, a difference in density and hardness in various directions. So moisture affects its physical strength, elasticity, and dimensional change. The effect of temperature is catalytic in several types of damage. In a very warm environment, it is dried and weakened, while the high temperature in a high relative humidity environment enhances the hydrolysis processes of wear, causing extensive deteriorations.

Uncontrolled drying result to abrupt removal of the water in the cell lumen and the hygroscopically bound water in the cell wall can lead to many types of damages, like collapse disintegration and shrinkage. Collapse is irreversible and recognized as flattened cells in cross-section, a very dense structure and "wavy" surface as shown in transversal section. Shrinkage is recognized as cracksboth in the longitudinal and transversal direction of the wood (Figures 15A \& B). Disintegration and warping are caused by both collapse and shrinkage. Woods shape gets distorted with cracks and splits, while precipitating salts and corrosion products
(A)

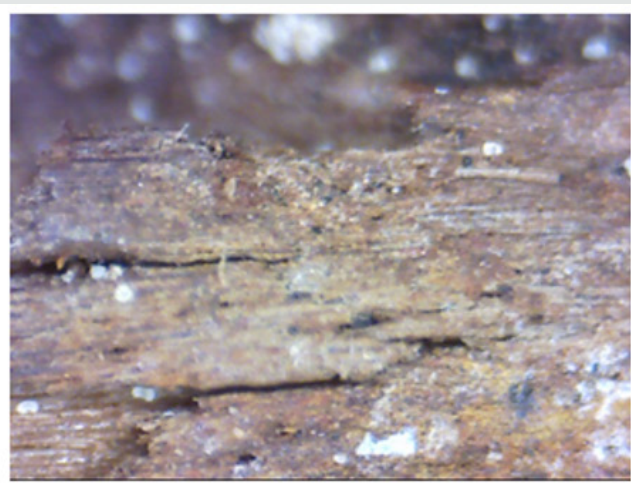

(B)

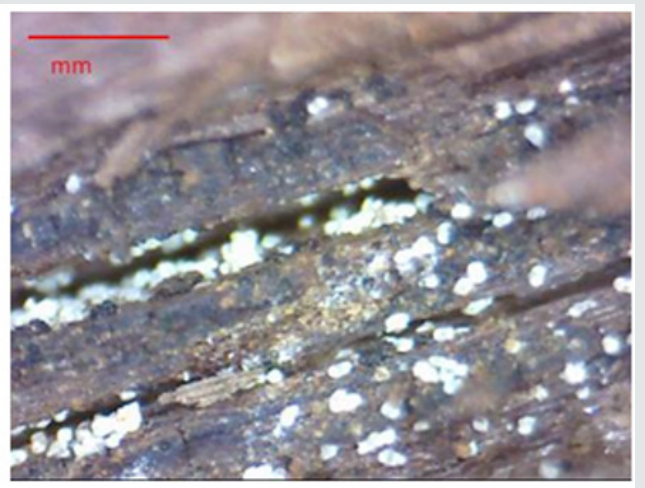

Figure 15: A) microscopic observation (via a DigiMicro USB Microscope 1.3Mpix- 200X) of wood showing A) cracks and B) splits with salt and corrosion products. 
The problem of wood degradation due to marine organisms [13], occurs when the water recedes in the summer months, as sufficient oxygen allows them to survive and retreat to the wood. These are the fungi that are usually above the waterline (Figure 14B), while worms that attack mainly the sunken wood do not cause damage as the ship is exposed beyond a marine environment for longer time. Contaminants that form suspended particles, sulfur dioxide, nitrogen, ozone, hydrogen sulfide, chlorides cause degradation of wood fibers, reduce mechanical strength, and chemical erosion. Wind action carries sand grains whose friction and impact cause erosion and aesthetic pollution (Figure15A). Salts from the sea cause separation of wood fibers (Figure15B).

The knots, the various cracks and all the imperfections of the wood, cause pressure and movement. Some spots have extensive loss of paint and varnish, while elsewhere the wood is completely exposed. Light has weakened the cellular structure of the wood and has broken the lignin bonds. Especially at the deck where the ultraviolet radiation of the sun is direct.

Finally, the most important damage that the wooden elements of the ship have suffered from are the metallic points with which they come in contact, but also the nails used for their joining (Figure 16). Extensive oxidation causes enormous mechanical pressures and therefore cracks and deformations, as well as coloring [14]. The wood degrades around metal because acid accumulates in the crevice where the chloride ions migrate accelerating the corrosion rate and so acid is produced. In seawater were soluble chloride salts are present the acid condition will develop quicker while at the same time, an additional reaction between iron ions and wood will be developed causing more deterioration [15-32].

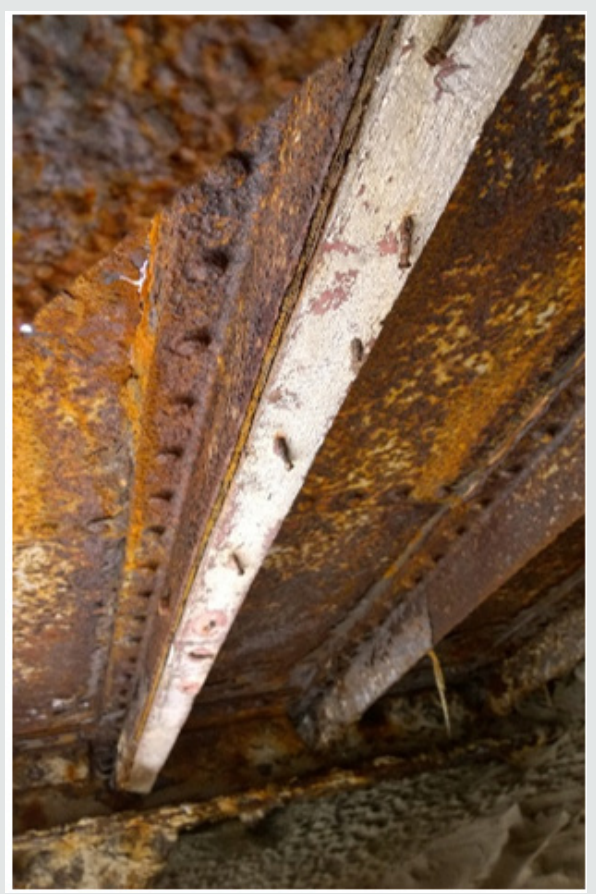

Figure 16: Detail of wood in contact with the metal surface.

\section{Conclusion}

Preserving a unique cultural item such as Navagio, through its significant historic resources gives a community its unique character. Furthermore, that navagio is exposed and suffer every year from the extreme changes of the environmental conditions. Many experts believe that the ship will eroded and lost its stability totally at the near future.

Taking into consideration the first documentation attempt, the dilemmas for the preservation of the Navagio are crusial and complex. The stability of Navagio is a complex issue which different experties should be considered. The overal preservation state of the Navagio is very poor and further preservation plan should be immediatelly drawn. Furthermore, the full documentation \& conservation of the Shipwreck (Navagio) of Zakynthos will provide and preserve a global tourism spot for the island and generally for Greece. Therefore, the owners and the public insitutions in Zakynthos which they are responsible for Navagio should consider that the future preservation of the Shipwreck (Navagio) of Zakynthos are beneficial to the community in many ways. The Shipwreck will attract more visitors in the future seeking heritage tourism opportunities. Finally, from a sociological point of view the community of Zakynthos will benefit when citizens preserve history and mutual concern for the protection of the shipwreck.

\section{Acknowledgement}

We would like to acknowledge the Archimandrite Dionysios Lykogiannis for giving us permission for using a photo of the ship during winter times.

\section{References}

1. Beltrame C (2013-2014) In-situ conservation of the Shipwrecks in the Mediterranean Sea, Corso di Laurea magistrale (ordinamento ex D.M. 270/2004) in Scienze dell'Antichità: Letterature, Storia e Archeologia (classe LM-2 - Classe delle lauree magistrali in Archeologia). Univesita Ca 'Foscari Venezia, Italy.

2. Barkai O, Kahanov Y, andAvissar M (2010) The Tantura F Shipwreck: The Ceramic Material Levant 42(1): 88-101.

3. Ruppe CV, Barstad JF (2002) International Handbook of Underwater Archaeology. Springer Science + Business Media, Germany.

4. Archaeology Online Magazine (2012) Ancient Shipwrecks found due to the "Poseidon" Project.

5. Asteri E (2019) The impressive Shipwreck "Dimitrios" in Valtaki, Gytheio. Happy Traveler Website.

6. INA Kyrenia Shipwreck Excavation. Institute of Nautical Archaeology, USA.

7. Katzev WS (2005) Resurrecting an Ancient Greek Ship: Kyrenia, Cyprus. In Bass GF(Ed.) Thames \& Hudson Beneath the Seven Seas, New York, USA, p: 72-79.

8. Hodges ERS, Guild of Natural Science Illustrators (U.S) (2003) The Guild Handbook of Scientific Illustration. John Wiley and Sons, New Jersey, USA.

9. Selwyn LS, Sirois J, Argyropoulos V (1999) The corrosion of excavated archaeological iron with details on weeping and Akaganeite. Studies in Conservation 44(4): 217-232. 
10. Selwyn L (2004) Overview of archaeological iron: The corrosion problem, key factors affecting treatment, and gaps in current knowledge. Metal 04: Proceedings of the International Conference on Metals Conservation, Canberra, Australia, pp. 294-306.

11. Turgoose S (1982) Post-excavation changes in iron antiquities. Studies in Conservation 27(3): 97-101.

12. Demetriou A (2017) Management of Ancient Shipwrecks, Report on Supporting Maritime Archaeology in the Eastern Mediterranean. Honor Frost Foundation Website.

13. Gareth Jones EB, Eltringham SK (1971) Marine Borers and Fouling Organisms of Wood. OECD Portsmouth, England.

14. Baker A J (1980) Degradation of wood by products of metal corrosion USDA. Forest Service Research Paper. pp. 981-993.

15. Beckhoff B, Kanngießer B, Langhoff N, Wedell R, Wolff H (2006) Handbook of Practical X-Ray Fluorescence Analysis. Springer Verlag Berlin Heilderbeg, Germany.

16. Binda L, Saisi A, Tiraboschi C, Valle S, Colla C, et al. (2003) Application of sonic and radar tests on the piers and walls of the Cathedral of Noto. Construction and Building Materials 17(8): 613-627.

17. Broodbank C, and Strasser T F (1991) Migrant farmers and the Neolithic colonization of Crete. Antiquity 65 (247): 233-245.

18. Cavanagh WG, Laxton RR (1981) The structural mechanics of the Mycenaean tholos tomb. The Annual of the British School at Athens 76: 109-140.

19. Como M T (2009) The construction of Mycenaean Tholoi Proceedings of the Third International Congress on Construction History. Cottbus 3: 385-391.

20. Cosentino P, Martorana R (2001) The resistivity grid applied to wall structures: first results. Proceedings of the $7^{\text {th }}$ Meeting of the Environmental and Engineering Geophysical Society European Section Birmingham, United Kingdom.

21. https://pages.vassar.edu/realarchaeology/2018/09/16/conservationof-marine-encrustations-what-composites-of-marine-sediments-cantell-us-about-shipwrecks-artifacts-and-oceanic-environments/
22. Dirlik N (2012) The Tholos Tombs of Mycenaean Greece. Master's thesis in Classical Archaeology and Ancient History. Uppsala University, Sweden, pp. 129.

23. Evans Sir A (1929) The Shaft Graves and Bee-Hive Tombs of Mycenae and their Interrelation. MacMillan and Co, London, United Kingdom.

24. Fitzsimons RD (2006) Monuments of Power and the Power of Monuments: The Evolution of Elite Architectural Styles at Bronze Age Mycenae. Unpublished Ph.D. Dissertation, University of Cincinnati, USA.

25. Frazer J G (1898) Pausanias' Description of Greece, Translated with Commentary. MacMillan and Co, London, United Kingdom 4(1): 94-95.

26. Frizell BS, Santillo R (1984) The construction and structural behavior of the Mycenaean tholos tomb. Opuscula Atheniensia Journal 15: 137-141.

27. Galanakis Y (2007) The construction of the Aegisthus Tholos Tomb at Mycenae and the 'Helladic Heresy'. Annual of the British School at Athens, Greece 102: 239-256.

28. Liritzis I, Zacharias N (2011) Portable XRF of Archaeological Artifacts: Current Research, Potentials and Limitations. In: Shackley MS (Eds.) X-Ray Spectometry (XRF) in Geoarchaeology. Springer Science + Business Media pp.109-142.

29. Liritzis I, Kosmatos D (1995) Solar-climatic cycles in the tree-ring record from Parthenon. In Finkl CW (eds.) Holocene Cycles: Climate, sea levels and sedimentation. Journal of Coastal Research 17: 73-78.

30. Mantler M, Schreiner M (2000) X-Ray Fluorescence Spectrometry in Art and Archaeology. X-Ray Spectrom 29: 3-17.

31. Millard A (2001) The deterioration of bone. In Brothwell DR, and Pollard AM (Eds.), Handbook of Archaeological Science, Chichester. Wiley, USA, pp. 637-648.

32. Walker A (2012) The Emperor and the World: Exotic Elements and the Imaging of Middle Byzantine Imperial Power, Ninth to Thirteenth Centuries, Cambridge University Press, USA.

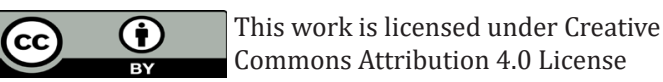

To Submit Your Article Click Here: Submit Article

DOI: $10.32474 / J A A S .2020 .01 .000124$

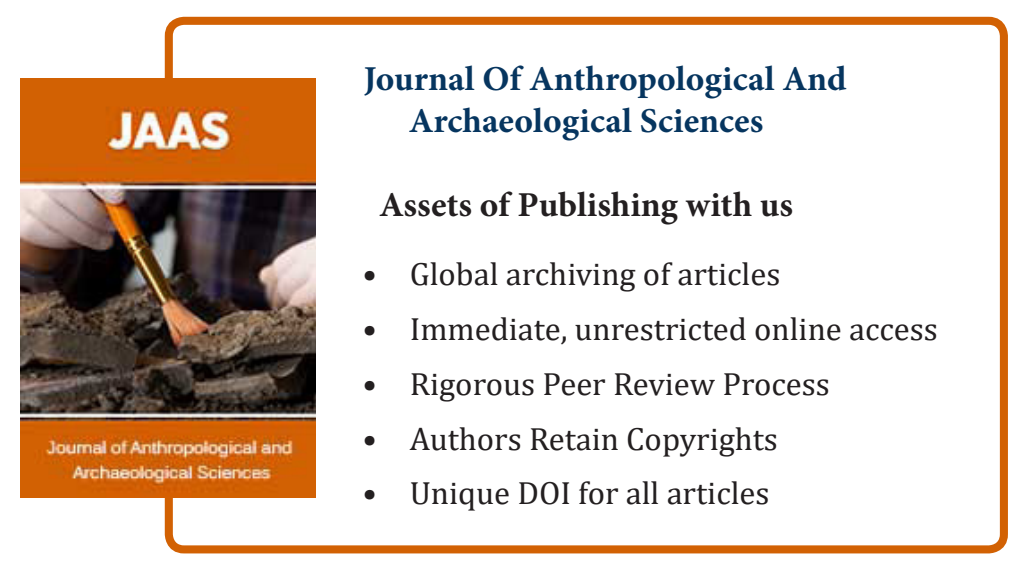

